Virginia Commonwealth University VCU Scholars Compass

2001

\title{
Energetics and electronic structure of carbon doped aluminum clusters
}

\author{
B. K. Rao \\ Virginia Commonwealth University \\ P. Jena \\ Virginia Commonwealth University
}

Follow this and additional works at: http://scholarscompass.vcu.edu/phys_pubs

Part of the Physics Commons

Rao, B. K., Jena, P. Energetics and electronic structure of carbon doped aluminum clusters. The Journal of Chemical Physics 115, 778 (2001). Copyright (C) 2001 AIP Publishing LLC.

\section{Downloaded from}

http://scholarscompass.vcu.edu/phys_pubs/156

This Article is brought to you for free and open access by the Dept. of Physics at VCU Scholars Compass. It has been accepted for inclusion in Physics Publications by an authorized administrator of VCU Scholars Compass. For more information, please contact libcompass@vcu.edu. 


\title{
Energetics and electronic structure of carbon doped aluminum clusters
}

\author{
B. K. Rao and P. Jena \\ Physics Department, Virginia Commonwealth University, Richmond, Virginia 23284-2000
}

(Received 13 September 2000; accepted 30 April 2001)

\begin{abstract}
The energetics and the electronic structure of $\mathrm{Al}_{n} \mathrm{C}$ clusters $(n=3,4,5 ; 11,12,13)$ have been studied by a global optimization of their geometry without any symmetry constraint. The total energies of these clusters both in neutral and charged states are calculated using an all-electron basis and the generalized gradient approximation to the density functional theory. While $\mathrm{Al}_{4} \mathrm{C}$ and $\mathrm{Al}_{12} \mathrm{C}$ clusters share some characteristic features of closed shell structures, namely enhanced stability and low electron affinity compared to their neighboring sizes, their ionization potentials exhibit different behavior. These decrease steadily from $\mathrm{Al}_{3} \mathrm{C}$ to $\mathrm{Al}_{5} \mathrm{C}$ while that of $\mathrm{Al}_{12} \mathrm{C}$ is higher than its neighbors. Carbon is found to form planar structures in small $\mathrm{Al}_{n} \mathrm{C}$ clusters $(n=3,4,5)$ irrespective of their charge state although neutral $\mathrm{Al}_{4} \mathrm{C}$ possesses a nearly degenerate tetrahedral isomer lying slightly higher in energy from the planar configuration. The results agree well with experimental and previous theoretical data. In larger $\mathrm{Al}_{n} \mathrm{C}(n=11,12,13)$ clusters, carbon occupies an interior site. In $\mathrm{Al}_{12} \mathrm{C}$, carbon occupies the center of an icosahedron while it is off-centered in $\mathrm{Al}_{11} \mathrm{C}$ and $\mathrm{Al}_{13} \mathrm{C}$. As an electron is attached, the near degeneracies of the neutral $\mathrm{Al}_{4} \mathrm{C}$ is lifted whereas nondegenerate isomers of neutral $\mathrm{Al}_{12} \mathrm{C}$ yield nearly degenerate anions. Both these features produce complicated photoelectron spectra making identification of their adiabatic electron affinity a difficult problem. With the exception of neutral $\mathrm{Al}_{12} \mathrm{C}$, the bonding of carbon to aluminum atoms is governed primarily by covalent interaction. The above calculations were also performed with a simplified basis by freezing the atomic cores of aluminum. In most cases, this simple basis yields results in good agreement with all electron calculations. (C) 2001 American Institute of Physics.
\end{abstract}

[DOI: 10.1063/1.1379973]

\section{INTRODUCTION}

The electronic structures of aluminum and carbon in the bulk phase are very different from those in clusters. Bulk aluminum is a trivalent metal where the conduction electrons are nearly free electronlike. In small clusters containing less than seven atoms, aluminum, due to its large energy gap between the $3 s$ and $3 p$ states, has been found to behave as a monovalent atom. ${ }^{1,2}$ The electrons in carbon, on the other hand, form covalent bonds. There are two forms of bulk carbon-diamond and graphite. In diamond the $s p^{3}$ character of electrons leads to tetrahedral bonds where carbon is fourfold coordinated while in graphite the $s p^{2}$ character of the electrons gives rise to a planar structure with threefold coordination. It is not common for carbon to form fourfold coordinated planar structures although exotic bonding behavior of carbon in fullerenes has been discovered. ${ }^{3}$ Much less information is available on how the bonding of carbon with metal atoms evolves from clusters to crystals. Consider, for example, bulk aluminum carbide. This has a saltlike structure with each carbon atom surrounded by aluminum atoms at distances from $1.90 \AA$ to $2.22 \AA$ and at ordinary temperatures it does not conduct electricity. What is not well understood is how the bonding of carbon evolves in small Al clusters. For example, (1) does carbon form tetrahedral bonds with $\mathrm{Al}$ atoms and (2) does aluminum behave as a monovalent atom while reacting with carbon in small $\mathrm{Al}_{n} \mathrm{C}(n<7)$ clusters?

A few years ago we had suggested ${ }^{4}$ that $\mathrm{Al}_{12} \mathrm{C}$ cluster could be considered as a magic cluster. Considering the valence of $\mathrm{Al}$ to be 3 and that of carbon to be 4, and assuming that carbon does not form covalent bonds with aluminum, $\mathrm{Al}_{12} \mathrm{C}$ would contain 40 valence electrons. In the jellium model of a cluster which is valid for nearly free-electron systems, 40 electrons are just enough to close $1 s^{2} 1 p^{6} 1 d^{10}$ $2 s^{2} 1 f^{14} 2 p^{6}$ shells. This electron shell closure should render $\mathrm{Al}_{12} \mathrm{C}$ enhanced stability over its neighboring clusters, and it was suggested that the weak reactivity of magic clusters would enable the use of $\mathrm{Al}_{12} \mathrm{C}$ clusters as a building block of a new kind of crystals - crystals of clusters. It was assumed that the likely structure of $\mathrm{Al}_{12} \mathrm{C}$ would be that of an icosahedron with carbon occupying the central site while $12 \mathrm{Al}$ atoms form the surface. This seemed to be a logical starting point as $\mathrm{Al}_{13}$ cluster was known to be icosahedric. Since this early calculation, several theoretical studies ${ }^{5-7}$ using molecular statics and dynamics have appeared that have verified the stability of the $\mathrm{Al}_{12} \mathrm{C}$ cluster in the icosahedric phase. Furthermore, it was also found that $\mathrm{Al}_{12} \mathrm{C}$ is thermally very stable with a melting temperature that exceeds even that of bulk Al. No extensive geometry optimizations starting with different initial configurations has been attempted to our knowledge to determine if the global equilibrium geometry of $\mathrm{Al}_{12} \mathrm{C}$ is, indeed, a perfect icosahedron or this simply represents a local minimum protected by a large energy barrier in the potential energy surface.

One of the characteristics of magic clusters, in addition to their unusual stability, is that they have higher ionization potential and lower electron affinity than their neighbors. Furthermore, there is a characteristic simplicity associated with the photodetachment spectra of closed shell clusters. No 
experiments, to our knowledge, have yet appeared to shed light on the electronic structure of $\mathrm{Al}_{12} \mathrm{C}$.

If the ground state structure of $\mathrm{Al}_{12} \mathrm{C}$ is, indeed, a perfect icosahedron, the bonding of carbon to $12 \mathrm{Al}$ atoms instead of the traditional threefold or fourfold coordination would once again reveal the exotic chemistry of one of the most ubiquitous elements in nature. To address this issue more fully than has hitherto been attempted, we have carried out a thorough investigation of the structure and properties of not only $\mathrm{Al}_{12} \mathrm{C}$, but also of its neighbors, $\mathrm{Al}_{11} \mathrm{C}$ and $\mathrm{Al}_{13} \mathrm{C}$. In addition to the extensive geometry optimization of $\mathrm{Al}_{n} \mathrm{C}(n$ $=11,12,13)$ clusters, we have computed their vertical ionization potential and adiabatic electron affinity. These values combined with the relative stability of these clusters not only provide a unique perspective of the magic $\mathrm{Al}_{12} \mathrm{C}$ cluster but also the electronic structure of carbon in hypermetallic systems. We have also performed calculations on small $\mathrm{Al}_{n} \mathrm{C}$ $(n \leqslant 5)$ clusters to compare our results with recent experimental and theoretical studies ${ }^{8-11}$ and thus to validate the accuracy of our computational procedure. In the following, we provide details of our theoretical procedure, results, and conclusions.

\section{THEORETICAL PROCEDURE}

The calculations were carried out using the molecular orbital theory where the cluster wave function is expressed as a linear combination of atomic orbitals centered at individual atomic sites. We have used three different basis sets: ${ }^{12}$ frozen core orbitals (LanL2DZ basis), all-electron basis $\left(6-311 \mathrm{G}^{* *}\right)$ of triple zeta quality with polarization functions, and $6-311 \mathrm{G}^{* *}$ basis with added diffuse functions. For carbon, in the LanL2DZ basis the core was not frozen. The global optimization of the geometries of large $\mathrm{Al}_{n} \mathrm{C}$ clusters $(n=11,12,13)$ is a difficult task, particularly if it is carried out without any symmetry restrictions, for various spin multiplicities, and for different random starting configurations. To facilitate this process we first used the frozen core basis to obtain the global equilibrium geometry of the clusters. These geometries were then used as starting configurations in a reoptimization scheme using all electron basis. While the frozen core basis worked very well in most pure Al clusters, its accuracy was limited in cases where clusters possess degenerate isomers. For example, $\mathrm{Al}_{13}$ possesses two isomers: decahedron and icosahedron. While the former was found to be $0.43 \mathrm{eV}$ lower in energy than the latter in a frozen core calculation, reverse was the case when an all-electron $6-311 \mathrm{G}^{* *}$ basis was used. Here, the icosahedron lies 0.23 $\mathrm{eV}$ lower in energy than the decahedron. We will show that similar uncertainties exist in $\mathrm{Al}$ clusters interacting with carbon only in isolated cases.

To further test the accuracy of the $6-311 \mathrm{G}^{* *}$ basis, we have repeated the studies of neutral and anionic $\mathrm{Al}_{4} \mathrm{C}$ cluster using the $6-311 \mathrm{G}^{* *}$ basis with added diffuse functions. The choice of $\mathrm{Al}_{4} \mathrm{C}$ to test the basis was made because extensive studies using different bases and exchange correlation treatment have been done by Boldyrev et al. ${ }^{8}$ and $\mathrm{Li}$ et al. ${ }^{9} \mathrm{We}$ will show that the results of the $6-311 \mathrm{G}^{* *}$ basis are almost identical to those obtained using additional diffuse functions. Consequently studies of the larger clusters were carried out

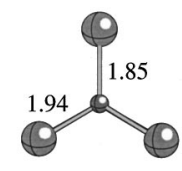

(a)

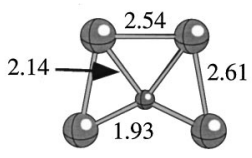

(c)

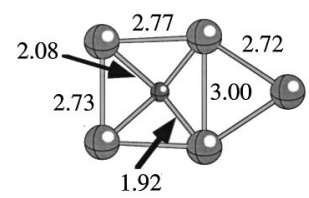

(e)

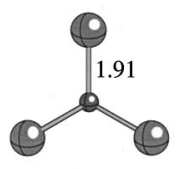

(b)

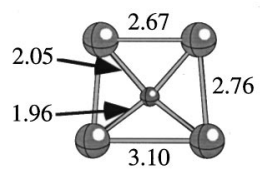

(d)

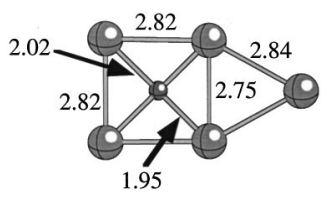

(f)

\section{Neutral}

Anion

FIG. 1. Ground state geometries of neutral and anionic $\mathrm{Al}_{n} \mathrm{C}(n=3,4,5)$ clusters obtained from the $6-311 \mathrm{G}^{* *}$ basis. The smaller spheres correspond to the carbon atoms and the larger spheres represent the aluminum atoms.

only with the $6-311 \mathrm{G}^{* *}$ basis. The total energies were calculated using the density functional theory (DFT) and the generalized gradient approximation (GGA) for the exchangecorrelation functional due to Becke, Perdew, and Wang (commonly referred to as BPW91). ${ }^{13}$ The calculations were carried out using the GAUSSIAN 94 program. ${ }^{12}$

\section{RESULTS AND DISCUSSIONS}

In Fig. 1 we provide the geometries of neutral and anionic form of $\mathrm{Al}_{3} \mathrm{C}, \mathrm{Al}_{4} \mathrm{C}$, and $\mathrm{Al}_{5} \mathrm{C}$ clusters obtained using

TABLE I. Total energies for $\mathrm{Al}_{n} \mathrm{C}$ systems in hartree units from LANL2DZ and the $6-311 \mathrm{G}^{* *}$ basis sets. The electronic states have been given where possible.

\begin{tabular}{|c|c|c|c|c|}
\hline \multirow[b]{2}{*}{ Cluster } & \multirow[b]{2}{*}{ Electronic state } & \multirow[b]{2}{*}{ Figure } & \multicolumn{2}{|c|}{$E$ (hartree) } \\
\hline & & & LANL2DZ & $6-311 G^{* *}$ \\
\hline $\mathrm{Al}_{3} \mathrm{C}$ & ${ }^{2} A_{1}$ & 1(a) & -44.02695 & -765.32935 \\
\hline $\mathrm{Al}_{3} \mathrm{C}^{-}$ & ${ }^{1} A_{1}^{\prime}$ & $1(b)$ & -44.10646 & -765.41408 \\
\hline $\mathrm{Al}_{4} \mathrm{C}$ (tet) & & & -46.06034 & -1007.79087 \\
\hline $\mathrm{Al}_{4} \mathrm{C}^{-}$(tet) & & & -46.12564 & -1007.85162 \\
\hline $\mathrm{Al}_{4} \mathrm{C}$ (planar) & & $1(\mathrm{c})$ & -46.04915 & -1007.79111 \\
\hline $\mathrm{Al}_{4} \mathrm{C}^{-}$(planar) & ${ }^{2} A^{\prime}$ & $1(\mathrm{~d})$ & -46.12818 & -1007.87141 \\
\hline $\mathrm{Al}_{5} \mathrm{C}$ & ${ }^{2} A_{1}$ & $1(\mathrm{e})$ & -48.06281 & -1250.23690 \\
\hline $\mathrm{Al}_{5} \mathrm{C}^{-}$ & ${ }^{1} A_{1}$ & $1(\mathrm{f})$ & -48.14724 & -1250.32250 \\
\hline $\mathrm{Al}_{11} \mathrm{C}$ & & 3(a),4(a) & -60.20140 & -2705.01210 \\
\hline $\mathrm{Al}_{11} \mathrm{C}^{-}$ & & $3(b), 4(b)$ & -60.29337 & -2705.10458 \\
\hline $\mathrm{Al}_{11} \mathrm{C}$ & ${ }^{2} B_{1}$ & $4(\mathrm{c})$ & -60.19785 & -2705.00658 \\
\hline $\mathrm{Al}_{11} \mathrm{C}^{-}$ & ${ }^{1} A_{1}$ & $4(d)$ & -60.28989 & -2705.09445 \\
\hline $\mathrm{Al}_{12} \mathrm{C}$ & & $3(\mathrm{c}), 2(\mathrm{a})$ & -62.27476 & -2947.53514 \\
\hline $\mathrm{Al}_{12} \mathrm{C}^{-}$ & & $2(d)$ & -62.33806 & -2947.59227 \\
\hline $\mathrm{Al}_{12} \mathrm{C}$ & & $2(\mathrm{c})$ & -62.27031 & -2947.51767 \\
\hline $\mathrm{Al}_{12} \mathrm{C}^{-}$ & ${ }^{2} A_{1}$ & $3(d), 2(b)$ & -62.35303 & -2947.59877 \\
\hline $\mathrm{Al}_{13} \mathrm{C}$ & & $3(\mathrm{e})$ & -64.28770 & -3189.97571 \\
\hline $\mathrm{Al}_{13} \mathrm{C}^{-}$ & & $3(f)$ & -64.38623 & -3190.07485 \\
\hline
\end{tabular}


TABLE II. Comparison of the calculated dissociation energy, $\Delta$, adiabatic electron affinity, vertical detachment energy, and vertical ionization potential of $\mathrm{Al}_{n} \mathrm{C}$ clusters with experiment using different basis functions.

\begin{tabular}{|c|c|c|c|c|c|c|c|c|}
\hline \multirow[b]{2}{*}{$n$} & \multicolumn{2}{|c|}{$\begin{array}{l}\text { Adiabatic electron } \\
\text { affinity eV }\end{array}$} & \multicolumn{2}{|c|}{$\begin{array}{l}\text { Vertical detachment } \\
\text { energy }(\mathrm{eV})\end{array}$} & \multicolumn{2}{|c|}{$\begin{array}{l}\text { Vertical ionization } \\
\text { potential }(\mathrm{eV})\end{array}$} & \multicolumn{2}{|c|}{$\Delta(\mathrm{eV})$} \\
\hline & LanL2DZ & $6-311 \mathrm{G}^{* *}$ & $6-311 \mathrm{G}^{* *}$ & Expt. (Ref.) & LanL2DZ & $6-311 \mathrm{G}^{* *}$ & LanL2DZ & $6-311 \mathrm{G}^{* *}$ \\
\hline 3 & 2.16 & 2.30 & 2.57 & $2.56 \pm 0.06$ (Ref. 8) & 9.28 & 8.71 & 6.71 & 6.78 \\
\hline 4 & 1.85 & 2.18 & 2.49 & $2.65 \pm 0.06$ (Ref. 9) & 6.85 & 6.95 & 7.17 & 7.32 \\
\hline 5 & 2.30 & 2.33 & 2.55 & $2.67 \pm 0.03$ (Ref. 10) & 6.60 & 6.55 & 6.60 & 6.88 \\
\hline 11 & 2.50 & 2.52 & 2.67 & & 6.08 & 6.23 & 5.99 & 6.07 \\
\hline 12 & 2.13 & 1.73 & 2.56 & & 6.93 & 6.77 & 6.51 & 7.40 \\
\hline 13 & 2.68 & 2.70 & 2.87 & & 6.01 & 6.07 & 5.98 & 5.84 \\
\hline
\end{tabular}

the all-electron 6-311G** basis. The corresponding total energies are given in Table I. Note that neutral $\mathrm{Al}_{3} \mathrm{C}$ has a $C_{2 v}$ structure with a short $\mathrm{Al}-\mathrm{C}$ bond of $1.85 \AA$ and two long $\mathrm{Al}-\mathrm{C}$ bonds of $1.94 \AA$. The corresponding distances obtained with LanL2DZ basis are $1.89 \AA$ and $1.98 \AA$. As an electron is attached, the structure of $\mathrm{Al}_{3} \mathrm{C}^{-}$assumes a $D_{3 h}$ symmetry with the Al-C bond length of $1.91 \AA$. This bond length agrees very well with $1.95 \AA$ calculated using the LanL2DZ basis. These bond lengths also agree very well with the all-electron calculations of Boldyrev et al. ${ }^{8}$ who used three different levels of theory as well as with those of Ashman et al. ${ }^{11}$ who used density functional theory and Perdew, Burke, and Ernzerhof formula ${ }^{14}$ for the GGA. The adiabatic electron affinities (which measure the difference in the energy between the ground states of the anion and neutral), the vertical electron detachment energy (i.e., the energy necessary to remove an electron from the anionic cluster without changing its geometry), and vertical ionization potentials (i.e., the difference in total energy of the ground state of the neutral and the cation with the neutral geometry) calculated using both basis functions are compared with available experiment ${ }^{8-10}$ in Table II. These calculated results, using two different basis sets agree well with each other for $\mathrm{Al}_{3} \mathrm{C}$ and $\mathrm{Al}_{5} \mathrm{C}$ while the discrepancy is larger in $\mathrm{Al}_{4} \mathrm{C}$. Note that similar level of uncertainty is also inherent with the choice of functionals for the exchange correlation potential. For example, Boldyrev et al. ${ }^{8}$ have calculated the adiabatic electron affinity of $\mathrm{Al}_{3} \mathrm{C}$ to be $2.40 \mathrm{eV}$, using the DFT method and B3LYP form for exchange and correlation potential while our all-electron value is $2.30 \mathrm{eV}$.

The ground state of the neutral $\mathrm{Al}_{4} \mathrm{C}$ cluster in $6-311 G^{* *}$ basis was found to be a slightly Jahn-Teller distorted planar $D_{4 h}$ structure (see Fig. 1). However, as mentioned before, a three-dimensional structure with a distorted tetrahedral symmetry was found to lie only $0.0065 \mathrm{eV}$ above the ground state. Two different theoretical groups have recently published results on $\mathrm{Al}_{4} \mathrm{C}$. Li et al. ${ }^{9}$ have reported the ground state of $\mathrm{Al}_{4} \mathrm{C}$ to have $T_{d}$ symmetry while Ashman et $a l .{ }^{11}$ find the $T_{d}$ structure to be $0.09 \mathrm{eV}$ above the ground state distorted $D_{4 h}$ structure. It is not clear if Li et al. ${ }^{9}$ had searched for the existence of a planar structure for the neutral $\mathrm{Al}_{4} \mathrm{C}$.

The near degeneracy of the neutral $\mathrm{Al}_{4} \mathrm{C}$ is lifted as an electron is attached. The planar $\mathrm{Al}_{4} \mathrm{C}^{-}$is found to lie $0.54 \mathrm{eV}$ below the tetrahedral structure. We find the ground state of the anion to be also Jahn-Teller distorted from the planar $D_{4 h}$ geometry. This is in agreement with the results of Ashman et al. ${ }^{11}$ However, Li et al. ${ }^{9}$ have reported the structure of $\mathrm{Al}_{4} \mathrm{C}^{-}$to have $D_{4 h}$ symmetry. We reoptimized the geometry of $\mathrm{Al}_{4} \mathrm{C}^{-}$subject to the $D_{4 h}$ symmetry constraint, and the resulting structure was found to be $0.045 \mathrm{eV}(0.07$ $\mathrm{eV}$ ) above the distorted structure using the $6-311 \mathrm{G}^{* *}$ (LanL2DZ) basis. Note that these energy differences are rather small and fall within the uncertainties of the theoretical procedure such as basis set, numerical procedure, and treatment of many-electron effects.

To see if the near degeneracy of the neutral $\mathrm{Al}_{4} \mathrm{C}$ and its disappearance as an electron is added could be attributed to the basis set problem, we have repeated our studies of $\mathrm{Al}_{4} \mathrm{C}$ and $\mathrm{Al}_{4} \mathrm{C}^{-}$using an extended basis where diffuse functions are added to the $6-311 \mathrm{G}^{* *}$ basis. The results are presented in Table III. Note that the total energies calculated with and without diffuse functions differ very little from each other. As before, we found two different isomers for these clusters - one with a distorted tetrahedral geometry and the other having a planar structure. Both basis functions yield the ground state of $\mathrm{Al}_{4} \mathrm{C}^{-}$to be planar in agreement with the results of Boldyrev and co-workers. ${ }^{9}$ However, for the neu-

TABLE III. Comparison of results of $\mathrm{Al}_{4} \mathrm{C}$ and $\mathrm{Al}_{4} \mathrm{C}^{-}$obtained using an all-electron basis with polarization function $\left(6-311 \mathrm{G}^{* *}\right)$ and with polarization and diffuse functions $\left(6-311++\mathrm{G}^{* *}\right)$.

\begin{tabular}{lccccccc}
\hline \hline & \multicolumn{2}{c}{ Total energy (a.u.) } & & \multicolumn{2}{c}{$\begin{array}{c}\text { Adiabatic electron } \\
\text { affinity }(\mathrm{eV})\end{array}$} & \multicolumn{2}{c}{$\begin{array}{c}\text { Vertical detachment } \\
\text { energy }(\mathrm{eV})\end{array}$} \\
\cline { 2 - 4 } \multicolumn{1}{c}{ Cluster } & $6-311 \mathrm{G}^{* *}$ & $6-311++\mathrm{G}^{* *}$ & $6-311 \mathrm{G}^{* *}$ & $6-311++\mathrm{G}^{* *}$ & $6-311 \mathrm{G}^{* *}$ & $6-311++\mathrm{G}^{* *}$ \\
\hline $\mathrm{Al}_{4} \mathrm{C}$ (tet) & -1007.79087 & -1007.79376 & $\ldots$ & $\ldots$ & $\ldots$ & $\ldots$ \\
$\mathrm{Al}_{4} \mathrm{C}$ (planar) & -1007.79111 & -1007.79345 & $\ldots$ & $\ldots$ & $\ldots$ & $\ldots$ \\
$\mathrm{Al}_{4} \mathrm{C}^{-}$(tet) & -1007.85162 & -1007.85498 & 1.65 & 1.67 & 1.81 & 1.81 \\
$\mathrm{Al}_{4} \mathrm{C}^{-}$(planar) & -1007.87141 & -1007.87409 & 2.18 & 2.19 & 2.49 & 2.50 \\
\hline \hline
\end{tabular}


tral $\mathrm{Al}_{4} \mathrm{C}$ cluster, the basis without the diffuse functions yields a planar geometry which is lower in energy than the distorted tetrahedral geometry by $0.0065 \mathrm{eV}$. The reverse is the case when the diffuse functions are added. The tetrahedral geometry is lower in energy by only $0.0084 \mathrm{eV}$. We believe that these energy differences are too small to be meaningful at this level of theory. It is, therefore, safe to conclude that the ground state of neutral $\mathrm{Al}_{4} \mathrm{C}$ has two nearly degenerate structures, distorted tetrahedral and planar, and that the results based on the $6-311 \mathrm{G}^{* *}$ basis are reliable.

The calculated adiabatic electron affinities using the LanL2DZ basis and 6-311G* basis are compared in Table II. The adiabatic electron affinity calculated by Li et al. ${ }^{9}$ at the $\operatorname{CCSD}(\mathrm{T})$ level of theory is $1.93 \mathrm{eV}$ while that obtained by Ashman et al. ${ }^{11}$ is $2.17 \mathrm{eV}$. Our all-electron value is close to those of Ashman et al. No experimental assignment of the adiabatic electron affinity of $\mathrm{Al}_{4} \mathrm{C}$ has been made. It was argued that this is due to the different geometry of the neutral $\left(T_{d}\right)$ and the anion $\left(D_{4 h}\right)$ ground states. We believe that the existence of neutral $\mathrm{Al}_{4} \mathrm{C}$ in two nearly degenerate isomeric forms (Jahn-Teller distorted $T_{d}$ and $D_{4 h}$ ) could also contribute to this. We have calculated the vertical electron detachment energy for which experimental value is available. Our results for the vertical electron detachment energies with and without diffuse functions are $2.50 \mathrm{eV}$ and $2.49 \mathrm{eV}$, respectively. The corresponding experimental value ${ }^{9}$ is 2.65 $\pm 0.06 \mathrm{eV}$. The agreement is very good indeed. Note that the value obtained by Boldyrev and co-workers ${ }^{9}$ is $2.71 \mathrm{eV}$.

The structures of neutral and anionic $\mathrm{Al}_{5} \mathrm{C}$ are planar with carbon being fourfold coordinated to $\mathrm{Al}$ atoms. They are marginally distorted from the $C_{2 v}$ symmetry and are in agreement with the results of Boldyrev et al. ${ }^{10}$ Note that the structure of neutral and anionic $\mathrm{Al}_{5} \mathrm{C}$ obtained by Ashman et al. ${ }^{11}$ is three dimensional in the shape of a square bipyramid with a carbon and an aluminum atom on the cap sites of the four-atom basal plane. We have optimized the structure of the neutral and anionic $\mathrm{Al}_{5} \mathrm{C}$ in this structure and the resulting energies are found to be $0.35 \mathrm{eV}$ and $0.25 \mathrm{eV}$ higher than the structures given in Figs. 1(e) and 1(f), respectively. The vertical detachment energies calculated using LanL2DZ basis and $6-311 \mathrm{G}^{* *}$ basis are compared with each other and experiment in Table II. Note that the agreement is good.

The Al-C bond lengths in both neutral and anionic $\mathrm{Al}_{n} \mathrm{C}$ $(n=3,4,5)$ clusters vary between $1.85 \AA$ and $2.14 \AA$. This is very similar to the bond length of the AlC dimer which at the all-electron level is $2.00 \AA$. This suggests that the strong bonding of AlC prevails irrespective of cluster size and charge.

In Table II we also list the dissociation energy, $\Delta$ necessary to fragment an $\mathrm{Al}_{n} \mathrm{C}$ cluster to $\mathrm{Al}_{n}+\mathrm{C}$, namely,

$$
\Delta=-\left[E\left(\mathrm{Al}_{n} \mathrm{C}\right)-E\left(\mathrm{Al}_{n}\right)-E(\mathrm{C})\right],
$$

where $E$ is the total energy of the relevant cluster. We note that $\Delta$ for $\mathrm{Al}_{4} \mathrm{C}$ is larger than those in $\mathrm{Al}_{3} \mathrm{C}$ and $\mathrm{Al}_{5} \mathrm{C}$. In addition, the electron affinity of $\mathrm{Al}_{4} \mathrm{C}$ is lower than those of $\mathrm{Al}_{3} \mathrm{C}$ and $\mathrm{Al}_{5} \mathrm{C}$. These two characteristics permit $\mathrm{Al}_{4} \mathrm{C}$ to have the distinction of a magic cluster. However, the vertical ionization potential of $\mathrm{Al}_{4} \mathrm{C}$ is not larger than that of its neighbors-a behavior that is inconsistent with magic clusters. One could thus classify $\mathrm{Al}_{4} \mathrm{C}$ as a pseudomagic cluster. Note that in a jellium model, a cluster containing eight valence electrons is considered to be magic as this corresponds to electronic shell closure $\left(1 s^{2} 1 p^{6}\right)$. For $\mathrm{Al}_{4} \mathrm{C}$ to have eight valence electrons, aluminum must be considered as monovalent since carbon contributes four electrons. Since two of the three indicators of a magic cluster are present in $\mathrm{Al}_{4} \mathrm{C}$, one could conclude that $\mathrm{Al}$ behaves as a monovalent atom in $\mathrm{Al}_{4} \mathrm{C}$. $\mathrm{Li}$ et al. ${ }^{9}$ have also come to the same conclusion.

We now turn our attention to $\mathrm{Al}_{n} \mathrm{C}$ clusters for $n$ $=11,12,13$. It was suggested earlier ${ }^{4}$ that $\mathrm{Al}_{12} \mathrm{C}$ would contain 40 valence electrons and, hence, should be a magic cluster since they give rise to electronic shell closures. Several calculations were performed where the structure of $\mathrm{Al}_{12} \mathrm{C}$ was assumed to be icosahedral with carbon at the center. Note that the icosahedric structure does not contain carbon in either three- or four-coordinated environment. Extensive geometry optimization starting with different initial configurations, to our knowledge, have not been carried out. Thus, it is unclear if the $\mathrm{Al}_{12} \mathrm{C}$ icosahedric structure corresponds to the global minimum or represents one of the many local minima in the potential energy surface. Extensive geometry optimization is, therefore, necessary to locate other isomers. In addition, to confirm that $\mathrm{Al}_{12} \mathrm{C}$ is also a magic cluster, one needs to show that not only is it more stable than $\mathrm{Al}_{11} \mathrm{C}$ and $\mathrm{Al}_{13} \mathrm{C}$ but that its ionization potential and electron affinity should also bear the characteristic signatures discussed earlier. No previous work on $\mathrm{Al}_{11} \mathrm{C}$ and $\mathrm{Al}_{13} \mathrm{C}$ is available in the literature.

We begin our discussion with $\mathrm{Al}_{12} \mathrm{C}$. We started the optimization procedure with four initial precursors by first using the LanL2DZ basis. These are distorted icosahedric structure with carbon occupying the central and a surface site and a distorted decahedric geometry with, once again, carbon occupying the central and a surface site. Recall that the $\mathrm{Al}_{13}$ cluster has two nearly degenerate isomers, ${ }^{2}$ icosahedric and decahedric. All these optimizations led to a single equilibrium configuration which is a perfect icosahedron with the carbon occupying the central site [see Fig. 2(a)]. This structure was used as a starting configuration in the all-electron calculation, and the geometry was reoptimized. The resulting structure remained unchanged. The $\mathrm{Al}-\mathrm{C}$ distance in this structure is $2.55 \AA$ which is significantly larger than what we have seen in smaller $\mathrm{Al}_{n} \mathrm{C}(n<5)$ clusters, namely around 2 $\AA$. Thus, one can conclude that in this icosahedric structure, carbon not only fails to preserve its threefold or fourfold coordinated chemistry, but behaves more like a metal atom.

To search for alternate isomers, we started with a fifth initial configuration where the $\mathrm{Al}$ atoms were moved arbitrarily from the icosahedric configuration and the carbon atom was also displaced from the central site. The resulting optimized geometry obtained at the LanL2DZ level of basis was again used as the starting configuration in the allelectron calculation. The resulting geometry is shown in Fig. 2(c). Note that in this structure, carbon is found to be threefold coordinated to $\mathrm{Al}$ atoms with the shortest $\mathrm{Al}-\mathrm{C}$ bond of $2.13 \AA$. Interestingly, the energy of this structure is $0.48 \mathrm{eV}$ 
(c)

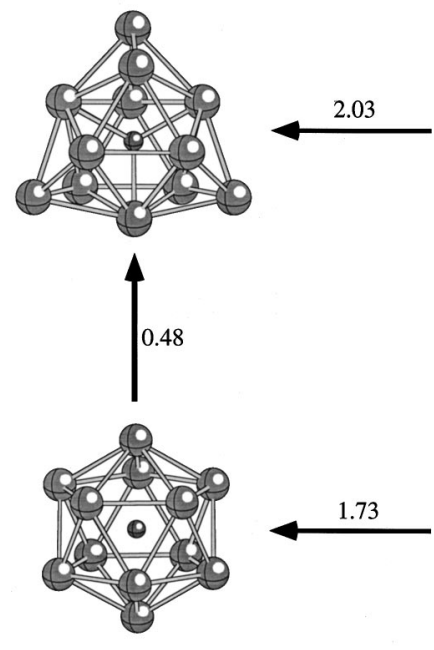

(a) (d)

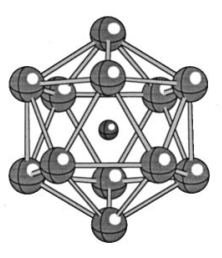

0.18

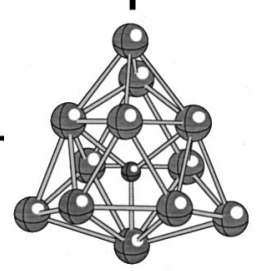

(b)
Anion

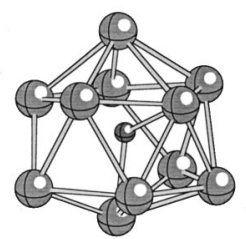

(a)

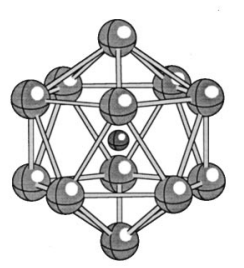

(c)

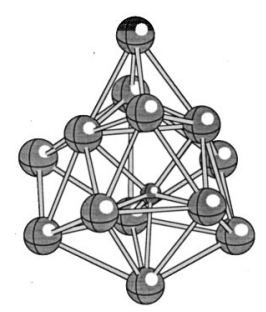

(e)

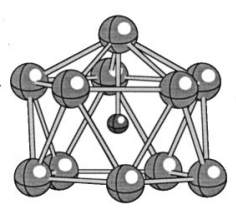

(b)

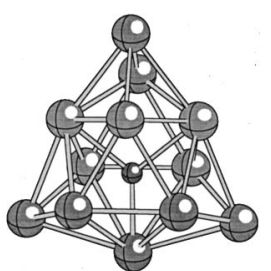

(d)

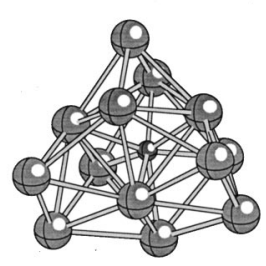

(f) presents the ground states while the upper row shows the lowest lying isomers. The results correspond to the all-electron calculations using the 6-311G** basis.

above the energy of the icosahedric structure. At this level of theory, this energy difference is large enough for us to conclude that the ground state of neutral $\mathrm{Al}_{12} \mathrm{C}$ is a perfect icosahedron. The results, are, however, somewhat different at the LanL2DZ level. The structure with threefold coordinated carbon [Fig. 2(c)] is $0.12 \mathrm{eV}$ higher in energy than the icosahedric structure. Although the LanL2DZ basis provides the same trend as that obtained using the $6-311 \mathrm{G}^{* *}$ basis, the energy difference between the two isomers of $\mathrm{Al}_{12} \mathrm{C}$ differ by $0.36 \mathrm{eV}$ from each other. We recall that the same level of discrepancy between the basis sets was also seen in $\mathrm{Al}_{4} \mathrm{C}$ (see Table II). Note that the icosahedric structure is stabilized by electronic shell closure whereas the $C_{2 v}$ structure [see Fig. 2(c)] is stabilized by the preference of carbon to preserve its covalent bonding behavior. It appears that in $\mathrm{Al}_{12} \mathrm{C}$, the influence of metallic bonding prevails.

We should expect this competition between electronic shell closure and covalency of carbon in $\mathrm{Al}_{12} \mathrm{C}$ cluster to disappear as an electron is attached to form anionic $\mathrm{Al}_{12} \mathrm{C}^{-}$. In this case the total number of electrons is 41 and no magic behavior is expected to emerge. We reoptimized the geometry of $\mathrm{Al}_{12} \mathrm{C}^{-}$by starting with neutral precursors in Figs. 2(a) and 2(c). The resulting anionic geometries are plotted in Figs. 2(b) and 2(d). We find that $\mathrm{Al}_{12} \mathrm{C}^{-}$in the $C_{2 v}$ structure [Fig. 2(b)] is $0.18 \mathrm{eV}$ energy lower than that with the icosahedriclike structure [Fig. 2(d)]. At the LanL2DZ level, the structure in Fig. 2(b) is lower in energy than that in Fig. 2(d) by $0.41 \mathrm{eV}$. Thus, the geometries of the ground state of the anion and neutral state of $\mathrm{Al}_{12} \mathrm{C}$ are very different. Consequently, as discussed for the case of $\mathrm{Al}_{4} \mathrm{C}$, the photoelectron spectra of $\mathrm{Al}_{12} \mathrm{C}^{-}$is expected to be complicated. We have learned that Wang and his group ${ }^{15}$ have indeed found the

Neutral

FIG. 3. Ground state geometries of neutral and anionic $\mathrm{Al}_{n} \mathrm{C}(n$ $=11,12,13$ ) clusters obtained from $6-311 \mathrm{G}^{* *}$ basis.

photodetachment spectra of $\mathrm{Al}_{12} \mathrm{C}^{-}$to be far more complicated than that of $\mathrm{Al}_{13}^{-}$.

To see if $\mathrm{Al}_{12} \mathrm{C}$ cluster still behaves like a magic cluster, we optimized the geometry of $\mathrm{Al}_{11} \mathrm{C}\left(\mathrm{Al}_{13} \mathrm{C}\right)$ clusters by first using the LanL2DZ basis and an initial structure where an $\mathrm{Al}$ atom was removed (added) arbitrarily from (to) the outer surface of the optimized $\mathrm{Al}_{12} \mathrm{C}$ cluster. The resulting optimized geometries were once again used as the starting configurations in a reoptimization scheme using the all-electron basis. The results are given in Figs. 3(a), 3(c), and 3(e). The structures of the corresponding anions were optimized by starting with neutral precursors first with the LanL2DZ basis and then with the $6-311 \mathrm{G}^{* *}$ basis. The results are also given in Figs. 3(b), 3(d), and 3(f). The two shortest Al-C bonds in neutral $\mathrm{Al}_{11} \mathrm{C}$ are $2.19 \AA$ and $2.22 \AA$ while the remaining distances exceed $2.49 \AA$. In $\mathrm{Al}_{11} \mathrm{C}^{-}$, there is only one $\mathrm{Al}-\mathrm{C}$ bond at $2.25 \AA$ while the others are longer than $2.49 \AA$. We have found low lying isomers of neutral and anionic $\mathrm{Al}_{11} \mathrm{C}$ which lie $0.15 \mathrm{eV}$ and $0.28 \mathrm{eV}$, respectively, above their corresponding ground states. These are shown in Fig. 4. Note that the higher energy isomers of neutral and anionic $\mathrm{Al}_{11} \mathrm{C}$ have threefold coordinated carbon with $\mathrm{Al}-\mathrm{C}$ bonds of 2.06 $\AA$, $2.21 \AA$, and $2.21 \AA$ in neutral [Fig. 4(c)] and 2.08 $\AA, 2.17$ $\AA$, and $2.17 \AA$ in the anionic [Fig. 4(d)] states. In $\mathrm{Al}_{13} \mathrm{C}$ clusters, there are six Al-C bonds between $2.0 \AA$ and $2.4 \AA$ in both neutral and anionic configurations.

The adiabatic electron affinities and vertical ionization potentials of $\mathrm{Al}_{11} \mathrm{C}$ and $\mathrm{Al}_{13} \mathrm{C}$ calculated using both basis functions are compared with those of $\mathrm{Al}_{12} \mathrm{C}$ in Table II. Note 
(c)

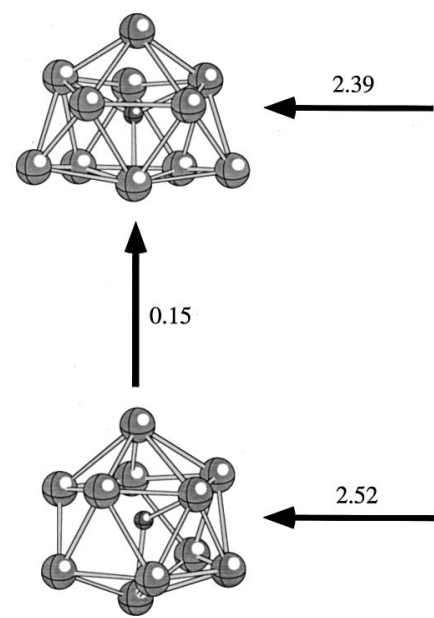

(a) (d)

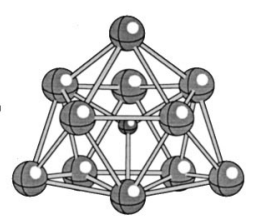

0.28

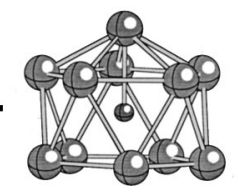

(b)
Anion

FIG. 4. Isomeric structures of neutral and anionic $\mathrm{Al}_{11} \mathrm{C}$ clusters showing the energies required to go from one structure to the other. The lower row gives the ground states and the upper row presents the lowest lying isomers.

that $\mathrm{Al}_{12} \mathrm{C}$ has a lower electron affinity than those of $\mathrm{Al}_{11} \mathrm{C}$ and $\mathrm{Al}_{13} \mathrm{C}$. On the other hand, the lowest ionization potential of $\mathrm{Al}_{12} \mathrm{C}$ is higher than those of $\mathrm{Al}_{11} \mathrm{C}$ and $\mathrm{Al}_{13} \mathrm{C}$. These characteristics of $\mathrm{Al}_{12} \mathrm{C}$ are consistent with a magic cluster.

We see that the magic behavior of $\mathrm{Al}_{12} \mathrm{C}$ is also supported by its dissociation energy $\Delta$, i.e., energy needed to dissociate $\mathrm{Al}_{n} \mathrm{C}$ to $\mathrm{Al}_{n}+\mathrm{C}$ (see Table II). Note that $\Delta$ for $\mathrm{Al}_{12} \mathrm{C}$ is larger than that for $\mathrm{Al}_{11} \mathrm{C}$ and $\mathrm{Al}_{13} \mathrm{C}$ implying that it is relatively more stable than either of its neighbors. Thus, relative binding, ionization potential, and electron affinity of $\mathrm{Al}_{12} \mathrm{C}$ cluster make it behave like a magic cluster.

\section{CONCLUSIONS}

The nature of bonding of carbon to aluminum clusters has been studied using the density functional theory with generalized gradient approximation for exchange and correlation and two different basis sets. The calculations were carried out using the GAUSSIAN 94 code. The results based on the simplified LanL2DZ basis provides the same essential physics as that obtained at the all-electron level. However, as expected, the quantitative accuracy of the results obtained at the LanL2DZ level of basis is limited. Following is a summary of our conclusions: (1) Carbon exhibits different bonding behavior in $\mathrm{Al}_{n} \mathrm{C}$ clusters depending on their size and charge state. In neutral $\mathrm{Al}_{4} \mathrm{C}$ cluster, carbon is bonded to four $\mathrm{Al}$ atoms in tetrahedral as well as planar configuration, while in $\mathrm{Al}_{4} \mathrm{C}^{-}$it forms a planar structure with fourfold coordination. The bonding of carbon is covalent. (2) The bonding of carbon in larger $\mathrm{Al}_{n}$ clusters $(n=11,12,13)$ exhibits a feature completely uncharacteristic of its chemistry. In $\mathrm{Al}_{12} \mathrm{C}$ cluster, carbon occupies the central site of a perfect icosahedron with no direct bond with any of the $\mathrm{Al}$ atoms. This is due to the electronic shell closure effect originating from the 40 valence electrons. This structure is energetically higher

than an isomer where carbon retains its threefold planar bonding scheme. In $\mathrm{Al}_{11} \mathrm{C}$ cluster there are two nearly degenerate structures. In one carbon it forms threefold coordination while in the other it forms two bonds in neutral $\mathrm{Al}_{11} \mathrm{C}$ and one bond in anionic $\mathrm{Al}_{11} \mathrm{C}^{-}$anion. (3) The dissociation energies of $\mathrm{Al}_{n} \mathrm{C}$ clusters indicate that $\mathrm{Al}_{4} \mathrm{C}$ cluster is more stable than $\mathrm{Al}_{3} \mathrm{C}$ and $\mathrm{Al}_{5} \mathrm{C}$. Similarly, $\mathrm{Al}_{12} \mathrm{C}$ is more stable than $\mathrm{Al}_{11} \mathrm{C}$ and $\mathrm{Al}_{13} \mathrm{C}$. The electron affinities of $\mathrm{Al}_{4} \mathrm{C}$ and $\mathrm{Al}_{12} \mathrm{C}$ clusters are lower than their neighbors. These features are characteristic of the magic clusters. The vertical ionization potential of $\mathrm{Al}_{12} \mathrm{C}$ also shows the trend consistent with magic clusters, but the same does not hold for $\mathrm{Al}_{4} \mathrm{C}$.

Another important characteristic of magic clusters is that a small perturbation such as addition or removal of an electron is not supposed to change their structure significantly. In that context, both $\mathrm{Al}_{4} \mathrm{C}$ and $\mathrm{Al}_{12} \mathrm{C}$ do not belong to the magic series as they undergo significant distortion when an electron is added. Thus, as $\mathrm{Al}_{12} \mathrm{C}$ clusters are assembled to form a solid structure, the interaction between $\mathrm{Al}$ atoms could make the synthesis of a crystal with $\mathrm{Al}_{12} \mathrm{C}$ as the building block difficult. ${ }^{6,7}$ Earlier molecular dynamics simulation ${ }^{6}$ of a crystal of $\mathrm{Al}_{12} \mathrm{C}$ has revealed that the structure was unstable and upon heating, it decomposed to units where $\mathrm{Al}_{4} \mathrm{C}$ was found to exist in molten Al. However, a recent study by $\mathrm{Gong}^{7}$ shows that when the orientational order between two $\mathrm{Al}_{12} \mathrm{C}$ icosahedra is properly taken into account, the crystal of this cluster can be metastable with a cohesive energy of $1.1 \mathrm{eV}$. Thus the idea of assembling crystals from magic clusters should be pursued by changing the composition and size such that the individual building blocks are stable against external perturbation.

\section{ACKNOWLEDGMENTS}

This work was supported in part by a grant from the Department of Energy (DEFG02-96ER45579). We are thankful to Professor L. S. Wang for valuable discussions.

${ }^{1}$ X. Li, H. Wu, X. B. Wang, and L. S. Wang, Phys. Rev. Lett. 81, 1090 (1998).

${ }^{2}$ B. K. Rao and P. Jena, J. Chem. Phys. 111, 1890 (1999).

${ }^{3}$ H. W. Kroto, J. R. Heath, S. C. O'Brien, R. F. Curl, and R. E. Smalley, Nature (London) 318, 162 (1985).

${ }^{4}$ S. N. Khanna and P. Jena, Phys. Rev. Lett. 69, 1664 (1992).

${ }^{5}$ X. G. Gong and V. Kumar, Phys. Rev. Lett. 70, 2078 (1993).

${ }^{6}$ A. P. Seitsonen, L. Laasonen, R. M. Nieminen, and M. L. Klein, J. Chem. Phys. 103, 8075 (1995).

${ }^{7}$ X. G. Gong, Phys. Rev. B 56, 1091 (1997).

${ }^{8}$ A. L. Boldyrev, J. Simmons, X. Li, W. Chen, and L. S. Wang, J. Chem. Phys. 110, 8980 (1999).

${ }^{9}$ X. Li, L. S. Wang, A. L. Boldyrev, and J. Simmons, J. Am. Chem. Soc. 121, 6033 (1999).

${ }^{10}$ A. L. Boldyrev, J. Simmons, X. Li, and L. S. Wang, J. Chem. Phys. 111, 4993 (1999).

${ }^{11}$ C. Ashman, S. N. Khanna, and M. R. Pederson, Chem. Phys. Lett. 324, 137 (2000).

${ }^{12}$ M. J. Frisch, G. W. Trucks, H. B. Schlegel et al., Gaussian 94, Revision B.1, Gaussian, Inc., Pittsburgh, PA, 1995. See also references therein for BPW91.

${ }^{13}$ J. P. Perdew, J. A. Chevary, S. H. Vosko, K. A. Jackson, M. R. Pederson, D. J. Singh, and C. Fiolhais, Phys. Rev. B 46, 6671 (1992); 48, 4978(E) (1993).

${ }^{14}$ J. P. Perdew, K. Burke, and M. Ernzerhof, Phys. Rev. Lett. 77, 3865 (1996).

${ }^{15}$ L. S. Wang (private communication). 